\title{
Influenza activity in Cambodia during 2006-2008
}

Sek Mardy1, Sovann Ly², Seng Heng2, Sirenda Vong1, Chea Huch²,

\author{
Chea Nora ${ }^{3}$, Nima Asgari ${ }^{3}$, Megge Miller ${ }^{3}$, Isabelle Bergeri ${ }^{3}$, Sybille Rehmet ${ }^{3}$, \\ Duong Veasna ${ }^{1}$, Weigong Zhou ${ }^{4}$, Takeshi Kasai ${ }^{4}$, Sok Touch ${ }^{2}$ and \\ Philippe Buchy*1
}

\begin{abstract}
Address: ${ }^{1}$ Institut Pasteur in Cambodia, 5 Monivong Blvd, Phnom Penh, Cambodia, ${ }^{2}$ Communicable Disease Control Department, Ministry of Health, \#151-153 Kampuchea Krom Blvd, Phnom Penh, Cambodia, ${ }^{3}$ World Health Organization, \#177-179 Pasteur Street, Khan Donpenh, Phnom Penh, Cambodia and ${ }^{4}$ World Health Organization, Regional Office for the Western Pacific, United Nations, Avenue, PO Box 2932,1000 Manila, Philippines

Email: Sek Mardy - mardy@pasteur-kh.org; Sovann Ly - sovann_ly@online.com.kh; Seng Heng - senghengcdc@yahoo.ca; Sirenda Vong - svong@pasteur-kh.org; Chea Huch - huch.cdc@gmail.com; Chea Nora - chean@wpro.who.int; Nima Asgari - asgarin@wpro.who.int; Megge Miller - nodularin@hotmail.com; Isabelle Bergeri - bergerii@wpro.who.int; Sybille Rehmet - sybillerehmet@yahoo.com; Duong Veasna - dveasna@pasteur-kh.org; Weigong Zhou - zhouw@wpro.who.int; Takeshi Kasai - kasait@wpro.who.int; Sok Touch - touch358@moh.gov.kh; Philippe Buchy* - pbuchy@pasteur-kh.org

* Corresponding author
\end{abstract}

Published: 15 October 2009

BMC Infectious Diseases 2009, 9:168 doi:10.1186/147/-2334-9-168
Received: 14 May 2009

Accepted: 15 October 2009

This article is available from: http://www.biomedcentral.com/I47I-2334/9//68

(c) 2009 Mardy et al; licensee BioMed Central Ltd.

This is an Open Access article distributed under the terms of the Creative Commons Attribution License (http://creativecommons.org/licenses/by/2.0), which permits unrestricted use, distribution, and reproduction in any medium, provided the original work is properly cited.

\begin{abstract}
Background: There is little information about influenza disease among the Cambodian population. To better understand the dynamics of influenza in Cambodia, the Cambodian National Influenza Center (NIC) was established in August 2006. To continuously monitor influenza activity, a hospital based sentinel surveillance system for ILI (influenza like illness) with a weekly reporting and sampling scheme was established in five sites in 2006. In addition, hospital based surveillance of acute lower respiratory infection (ALRI) cases was established in 2 sites.
\end{abstract}

Methods: The sentinel sites collect weekly epidemiological data on ILI patients fulfilling the case definition, and take naso-pharyngeal specimens from a defined number of cases per week. The samples are tested in the Virology Unit at the Institut Pasteur in Phnom Penh. From each sample viral RNA was extracted and amplified by a multiplex RT-PCR detecting simultaneously influenza $A$ and influenza $B$ virus. Influenza $A$ viruses were then subtyped and analyzed by hemagglutination inhibition assay. Samples collected by the ALRI system were tested with the same approach.

Results: From 2006 to 2008, influenza circulation was observed mainly from June to December, with a clear seasonal peak in October shown in the data from 2008.

Conclusion: Influenza activity in Cambodia occurred during the rainy season, from June to December, and ended before the cool season (extending usually from December to February). Although Cambodia is a tropical country geographically located in the northern hemisphere, influenza activity has a southern hemisphere transmission pattern. Together with the antigenic analysis of the circulating strains, it is now possible to give better influenza vaccination recommendation for Cambodia. 


\section{Background}

Influenza epidemics occur worldwide annually, resulting in considerable morbidity and causing 250,000 to 500,000 deaths annually worldwide [1]. The epidemiology and prevalence of influenza displays a seasonal pattern in temperate regions. Information concerning seasonality and prevalence is crucial for development of effective regional and global seasonal influenza prevention strategies as well as pandemic influenza control measures [2]. Data on the epidemiology of influenza however, are particularly limited in tropical countries $[2,3]$. To better describe the epidemiology, seasonality and disease burden of influenza as well as to minimize the impact of this disease, the World Health Organization (WHO) formed an Influenza Surveillance Network to detect the emergence and spread of new influenza antigenic variants, to use circulating strains characteristics information to update the formulation of influenza vaccine, and to provide as much warning as possible of the next pandemic. In 1952, WHO established an international laboratory-based surveillance network for influenza. The network currently consists of 125 National Influenza Centre (NIC) laboratories in 95 countries, and four WHO Collaborating Centers for Reference and Research on Influenza (WHO CC) [4].

Prior to the emergence of H5N1 related pandemic threat, influenza data were scarce in Cambodia as laboratory capacities were also limited. To better understand influenza in Cambodia, the NIC was established within a joint collaboration between the Center for Diseases Control Department/Ministry of Health and the Institut Pasteur in Cambodia (IPC) in August 2006. We summarize in this report data gathered from the Cambodian NIC which is based on sampling ILI patients from 5 sentinel outpatients' departments located across the country. Some of these sites were also selected for their proximity to neighboring countries since movement across the borders may result in importation of influenza strains. We also report influenza data during 2007 - 2009 from two hospitals in which IPC has collaborated with clinicians to determine bacterial and viral etiologies of inpatients with acute lower respiratory infections (ALRI).

\section{Methods}

\section{Geographic and climatic background}

Cambodia is a country in Southeast Asia, bordered by Thailand, Laos, Vietnam and the Gulf of Thailand. Cambodia covers 181,035 square kilometers and consists of 27 provinces. As a tropical country, the climate has marked dry and rainy seasons of relatively equal length with averaging temperatures ranging from 24 to 38 degrees Celsius. The dry season runs generally from November to April and the rainy season starts in May-June and ends in October-November.

\section{Study sites}

The ILI surveillance encompasses 5 outpatients' departments located in the following provincial or referral hospitals: Takeo (southern Cambodia), Battambang (western Cambodia), Kampong Cham (central-north Cambodia), a pediatric hospital in Siem Reap (north-west Cambodia) and the National Pediatric hospital in Phnom Penh capital (central Cambodia). Since April 2007, the Institut Pasteur in Cambodia (IPC) has also collaborated with Takeo and Kampong Cham provincial hospitals to study the etiologies of acute lower respiratory infections among hospitalized patients. Each sentinel and study site was required to randomly collect nasopharyngeal swabs of 5 to 10 ILI patients per week all year long. For the hospital study we obtained nasopharyngeal samples from all hospitalized patients admitted to the two hospital sites collaborating with ALRI study. Swab specimens were immediately introduced into a sterile tube containing virus transport medium (VTM), kept in liquid nitrogen containers and transported to the Institut Pasteur in Phnom Penh on a weekly basis.

\section{Surveillance and case definition}

Multiple respiratory viruses, including respiratory syncytial virus, parainfluenza viruses, adenovirus, and rhinovirus, can mimic influenza symptoms [5]. Since the middle of 2008, the following WHO definition of ILI was used: person with sudden onset of fever $>38^{\circ} \mathrm{C}$ armpit and cough or sore throat in the absence of other diagnosis [6]. From 2006 to early 2008, the ILI case definition was identical except for the fever criteria which was set at $\geq 37.5^{\circ} \mathrm{C}$ armpit temperature. For the ALRI study, all patients were recruited between April 2007 and March 2009. A case for the under 5 age group was defined as an illness of $<10$ days duration that consisted of cough or difficult breathing plus tachypnea. For the 5-14 age group, case definition included the above signs and symptoms plus fever $>38^{\circ} \mathrm{C}$ armpit on admission. For the 15 and over age group, a case was defined as anyone with fever $>38^{\circ} \mathrm{C}$ armpit on admission plus tachypnea or chest pain or auscultatory crackles. Clinical examination of cases was conducted by hospital clinicians and recorded alongside demographic information by means of a standard case report form and chest-X rays were systematically requested.

\section{Laboratory Methods}

The collected naso-pharyngeal samples were immediately frozen at the hospital in liquid nitrogen and the container was sent on a weekly basis to the IPC's Virology Unit where specimens were stored at $-80^{\circ} \mathrm{C}$ prior to testing. Viral RNA was extracted from $140 \mu \mathrm{L}$ of VTM by using the QIAamp Viral RNA Isolation Kit (QIAGEN, CA, USA) and amplified by multiplex reverse transcriptase-polymerase chain reaction (RT-PCR) detecting simultaneously influenza A virus, influenza B virus, respiratory syncytial virus 
and human metapneumovirus, as previously reported [7]. Influenza A viruses were subsequently subtyped by conventional RT-PCR methods targeting specifically H1, H3, $\mathrm{N} 1$ and N2 genes (protocols available upon request to authors). The influenza positive specimens were also inoculated onto MDCK cells as previously described [8]. The influenza strains were analyzed by a hemagglutination inhibition (HAI) test using a WHO influenza diagnostic kit [9]. A representative number of influenza isolates was sent each year to the WHO Collaborating Center in Melbourne, Australia, for further analysis (Table 1).

\section{Statistical analyses}

The comparisons between percentages and two means were tested by Chi2 test and Student's t test respectively. A p value $<0.05$ was considered significant. Proportions, means and all statistical analyses were performed using STATA 9.0 (Statacorp., college station, TX, Texas).

\section{Results}

The number of influenza strains identified during the 2006-2008 period by both ILI and ALRI systems are detailed in Table 1 and Figure 1.

ILI surveillance program tested a total of 3,148 samples during 2006-2008. The average age of the studied population was 11.9 years (range, 1 month-76 years) and $50.8 \%$ were male. Of these, $338(10.7 \%)$ tested positive. The average age of positive patients was 8.7 years (range, 1 month to 76 years) and $180(53.3 \%)$ were male. There were no differences in age and gender distribution across the three testing years. However, the influenza-infected patients were significantly younger than those tested negative for influenza viruses (8.7 versus 11.9 years; $\mathrm{p}<$ 0.001 ). Overall positive rates varied from $5.8 \%$ in 2006 , $7.7 \%$ in 2007 and $15.3 \%$ in 2008.

The average age among the patients included in the ALRI study was 38.2 years (range: 1 month to 87 years) and $61.8 \%$ were male. Of the 1,868 patients admitted with
ALRI during 2007-2008, only 64 (3.4\%) tested positive for influenza virus - $1.4 \%$ in 2007 and $3.6 \%$ in 2008 . The average age of positive cases was 15.2 years (range, 3 months to 82 years); 28 (51.7\%) were male. The patients with influenza infection were significantly younger than the other patients recruited in the ALRI study $(\mathrm{p}<0.001)$.

The difference between both ILI and ALRI system for influenza detection was significant $(p<0.001)$.

From 2006 to 2008, influenza infections were observed mainly from June to December (Figure 1). However, some influenza activity (mainly influenza B, but not exclusively) was also detected in March 2007. During this time a human case of influenza A/H5N1 infection was also identified by the NIC in a patient admitted in a reference hospital of the capital for severe pneumonia. Incidently, the H5N1 case detected in 2008 was identified during a fever surveillance study (Wierzba T, personal communication).

The proportion of influenza virus detected among ILI specimens from 2006 to early 2009 varies between $0 \%$ in April and May and 50\% in October 2008 (Figure 2). Influenza positivity rates varied between the sentinel sites: $40 \%$ in the National Pediatric hospital in Phnom Penh, 9.5\% in Takeo, $20 \%$ in Kampong Cham, $16 \%$ in Battambang and $14.5 \%$ in a pediatric hospital in Siem Reap. Only 5 to $10 \%$ of the ALRI specimens were positive for influenza virus during the highest transmission season (from September to November) (Figure 3).

The antigenic analysis show that influenza $\mathrm{A} / \mathrm{H} 1 \mathrm{~N} 1$ isolates belonged to the A/New Caledonia/20/99-like group in 2007 and A/Brisbane/59/2007-like group in 2008. In 2006 and 2007, A/H3N2 strains tested were close to A/ Wisconsin/67/2005-like, but in 2008 the strains drifted to A/Brisbane/10/2007-like. The influenza B strains were B/ Malaysia/2506/2004-like in 2007 and B/Florida/4/2006like in 2008. These data suggest that the influenza strains circulating in Cambodia from 2007 to 2008 match with

Table I: Breakdown of influenza positive isolates by type and subtype in $2006-2008$

\begin{tabular}{|c|c|c|c|c|c|c|c|c|c|c|}
\hline \multirow[t]{2}{*}{ Year } & \multirow[t]{2}{*}{ No. of specimens } & \multirow[t]{2}{*}{ No. of positives (\%) } & \multicolumn{2}{|c|}{ Type } & \multicolumn{3}{|c|}{ Subtype of influenza A } & \multicolumn{3}{|c|}{ WHOCC, Melbourne* } \\
\hline & & & $\begin{array}{c}\text { Influenza A } \\
\text { (\%) }\end{array}$ & $\begin{array}{c}\text { Influenza B } \\
(\%)\end{array}$ & $\begin{array}{c}\text { HIN I } \\
(\%)\end{array}$ & $\begin{array}{c}\text { H3N2 } \\
(\%)\end{array}$ & $\begin{array}{l}\text { H5NI } \\
(\%)\end{array}$ & HINI & H3N2 & Influenza B \\
\hline 2006 & 516 & $\begin{array}{c}30 \\
(5.8)\end{array}$ & $\begin{array}{c}30 \\
(100)\end{array}$ & 0 & 0 & $\begin{array}{c}30 \\
(100)\end{array}$ & 0 & N/A & 26 & $\mathrm{~N} / \mathrm{A}$ \\
\hline 2007 & 1827 & $\begin{array}{l}104 \\
(5.7)\end{array}$ & $\begin{array}{c}44 \\
(42.3)\end{array}$ & $\begin{array}{c}60 \\
(57.7)\end{array}$ & $\begin{array}{c}14 \\
(31.8)\end{array}$ & $\begin{array}{c}29 \\
(65.9)\end{array}$ & $\begin{array}{c}\text { I } \\
(2.3)\end{array}$ & 19 & 24 & 33 \\
\hline 2008 & 2673 & $\begin{array}{l}259 \\
(9.7)\end{array}$ & $\begin{array}{l}171 \\
(66)\end{array}$ & $\begin{array}{l}88 \\
(34)\end{array}$ & $\begin{array}{c}31 \\
(18.1)\end{array}$ & $\begin{array}{l}139 \\
(81.3)\end{array}$ & $\begin{array}{c}1 \\
(0.6)\end{array}$ & 3 & 18 & 6 \\
\hline
\end{tabular}

* Number of specimens sent to the WHO Collaborating Center in Melbourne from 2006 to 2008. 


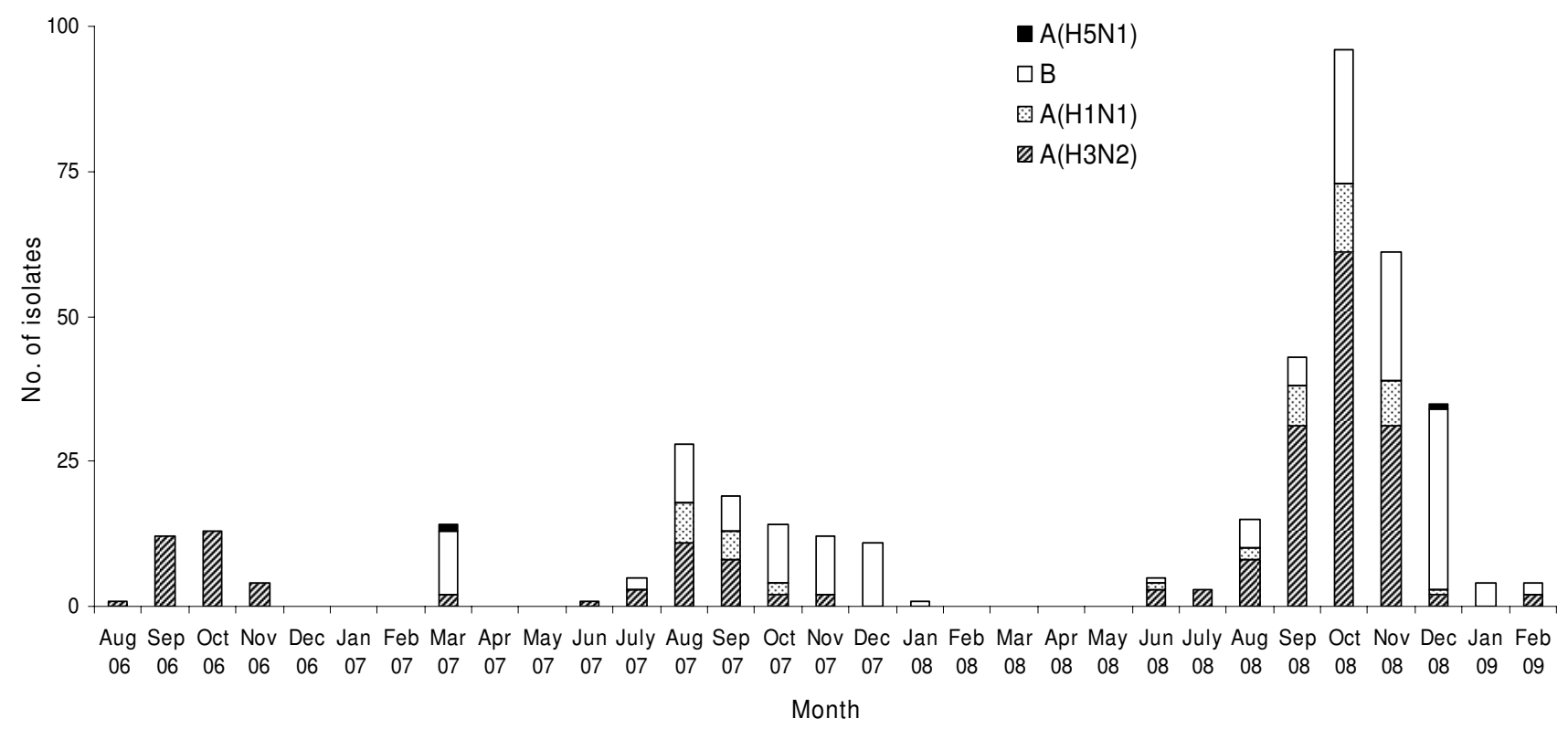

Figure I

Monthly distribution of influenza isolates from late 2006 to early 2009.

the strains contained in the influenza vaccine recommended for the southern hemisphere (Table 2). Nevertheless, in 2006, only $\mathrm{H} 3 \mathrm{~N} 2$ viruses were isolated in Cambodia and these strains belonged to the A/Wisconsin/ $67 / 2005$-like group while the seasonal vaccine for the southern hemisphere contained the A/California/7/2004like strain (Table 2).

\section{Discussion}

To our knowledge, this is the first report of influenza activity in Cambodia. It appears that there is a consistent pat-

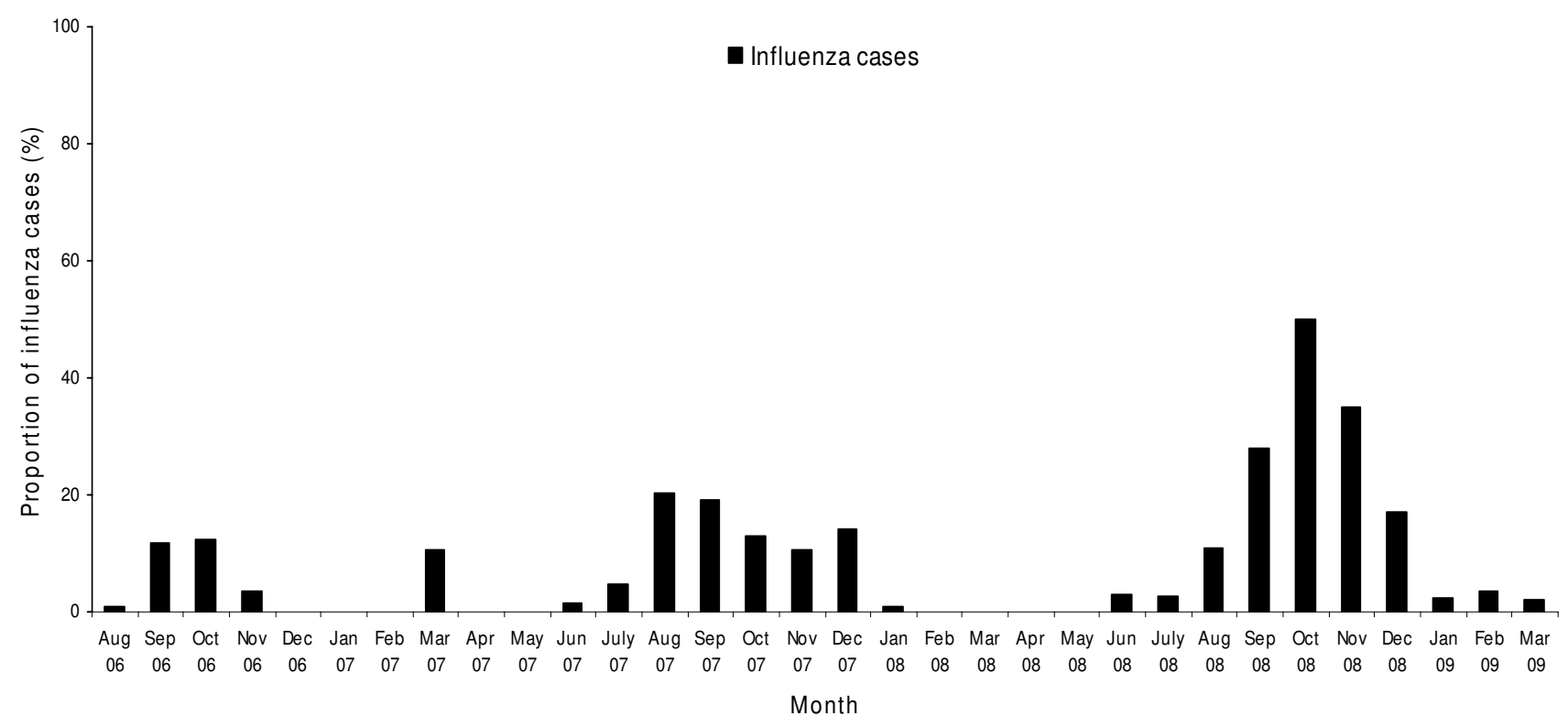

Figure 2

Monthly proportion of positive influenza samples among ILI specimens tested from late 2006 to early 2009. 


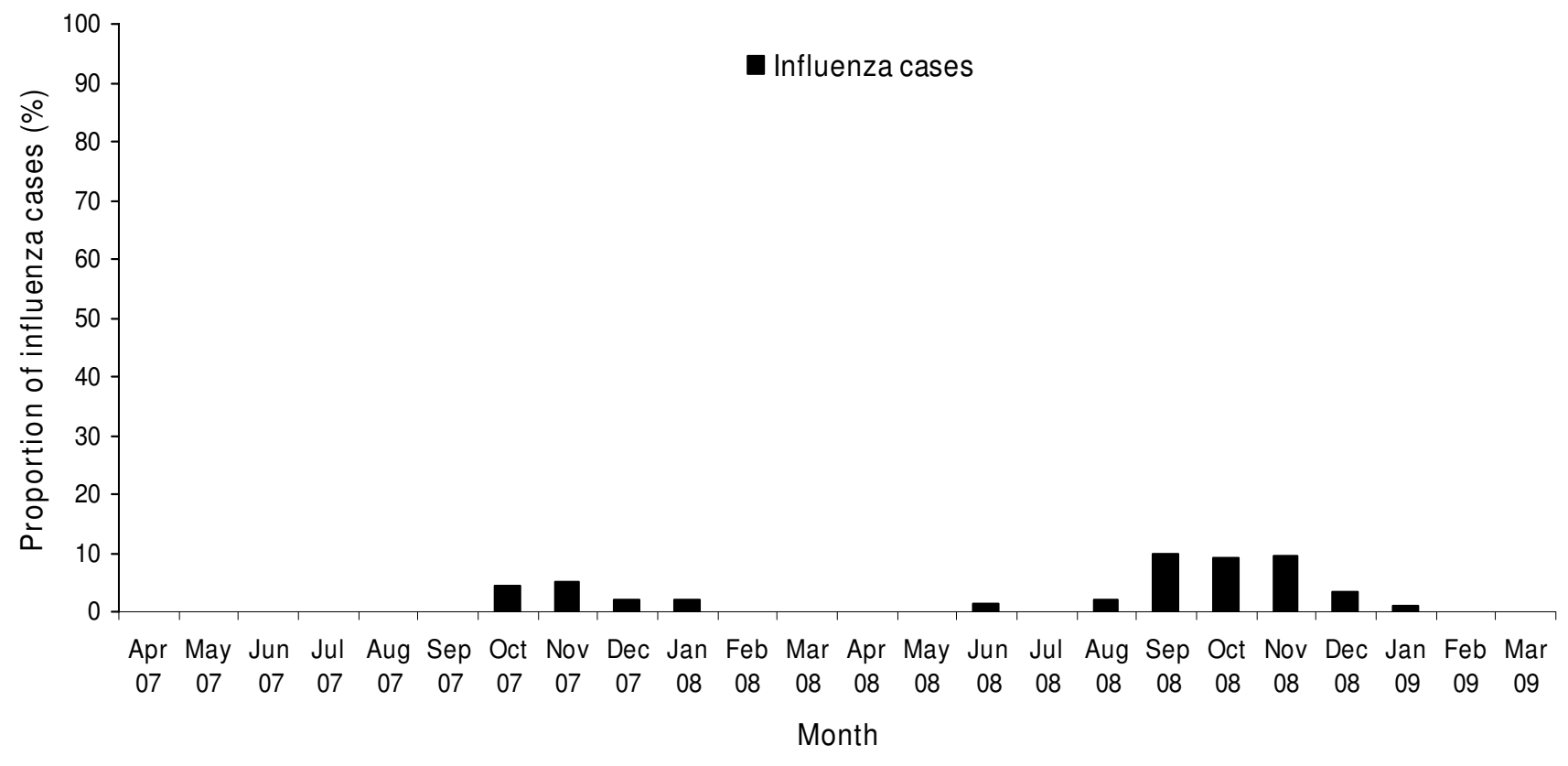

Figure 3

Monthly proportion of positive influenza samples among ALRI specimens tested from 2007 to early 2009.

tern of influenza seasonality during these 3 years, with detection peaking during the rainy season from June to December. During the hot and dry seasons there was little to no detection of influenza, apart from an unusual peak during March 2007, a period where increased influenza activity was detected at all 5 sentinel sites. This overall pattern contrasts with that of Northern Vietnam, Thailand or Singapore in which influenza viruses circulate year-round and appears more similar to that of countries of southern hemisphere (Australia, New Zealand) [10-13]. The rea-

Table 2: Comparison between vaccine strains and circulating influenza strains in Cambodia from 2006 to 2008.

\begin{tabular}{|c|c|c|c|c|c|c|}
\hline \multirow[t]{2}{*}{ Season } & \multicolumn{2}{|c|}{ A/HINI } & \multicolumn{2}{|c|}{ A/H3N2 } & \multicolumn{2}{|c|}{ Influenza B } \\
\hline & Vaccine stain & $\begin{array}{l}\text { Cambodian } \\
\text { strains }\end{array}$ & Vaccine strain & $\begin{array}{l}\text { Cambodian } \\
\text { strains }\end{array}$ & Vaccine strain & $\begin{array}{l}\text { Cambodian } \\
\text { strains }\end{array}$ \\
\hline 2006 & $\begin{array}{l}\text { A/New Caledonia/ } \\
\text { 20/1999-like }\end{array}$ & $N / A$ & $\begin{array}{l}\text { A/California/7/ } \\
\text { 2004-like }\end{array}$ & $\begin{array}{l}\text { A/Wisconsin/67/ } \\
\text { 2005-like }\end{array}$ & $\begin{array}{l}\text { B/Malaysia/2506/ } \\
\text { 2004-like }\end{array}$ & N/A \\
\hline $2006-2007$ & $\begin{array}{l}\text { A/New Caledonia/ } \\
\text { 20/1999-like }\end{array}$ & & $\begin{array}{l}\text { A/Wisconsin/67/ } \\
\text { 2005-like }\end{array}$ & & $\begin{array}{l}\text { B/Malaysia/2506/ } \\
\text { 2004-like }\end{array}$ & \\
\hline 2007 & $\begin{array}{l}\text { A/New Caledonia/ } \\
\text { 20/1999-like }\end{array}$ & $\begin{array}{l}\text { A/New Caledonia/ } \\
\text { 20/I999-like }\end{array}$ & $\begin{array}{l}\text { A/Wisconsin/67/ } \\
\text { 2005-like }\end{array}$ & $\begin{array}{l}\text { A/Wisconsin/67/ } \\
\text { 2005-like }\end{array}$ & $\begin{array}{l}\text { B/Malaysia/2506/ } \\
\text { 2004-like }\end{array}$ & $\begin{array}{l}\text { B/Malaysia/2506/ } \\
\text { 2004-like }\end{array}$ \\
\hline 2007-2008 & $\begin{array}{l}\text { A/Solomon Islands/3/ } \\
\text { 2006-like }\end{array}$ & & $\begin{array}{l}\text { A/Wisconsin/67/ } \\
\text { 2005-like }\end{array}$ & & $\begin{array}{l}\text { B/Malaysia/2506/ } \\
\text { 2004-like }\end{array}$ & \\
\hline 2008 & $\begin{array}{l}\text { A/Solomon Islands/3/ } \\
\text { 2006-like }\end{array}$ & $\begin{array}{l}\text { A/Brisbane/59/2007- } \\
\text { like }\end{array}$ & $\begin{array}{l}\text { A/Brisbane/I0/ } \\
\text { 2007-like }\end{array}$ & $\begin{array}{l}\text { A/Brisbane/I0/ } \\
\text { 2007-like }\end{array}$ & $\begin{array}{l}\text { B/Florida/4/2006- } \\
\text { like }\end{array}$ & $\begin{array}{l}\text { B/Florida/4/2006- } \\
\text { like }\end{array}$ \\
\hline 2008-2009 & $\begin{array}{l}\text { A/Brisbane/59/2007- } \\
\text { like }\end{array}$ & & $\begin{array}{l}\text { A/Brisbane/I0/ } \\
\text { 2007-like }\end{array}$ & & $\begin{array}{l}\text { B/Florida/4/2006- } \\
\text { like }\end{array}$ & \\
\hline
\end{tabular}

Bolded seasons correspond to the southern hemisphere. 
sons for the seasonality of influenza are not clearly known and are probably the result of a combination of multiple factors as, for instance, climate conditions, epidemiology (population's age, density, migration, etc.), host susceptibility and virus characteristics [14]. Others also reported that influenza seasonality coincides with rainy season [1518] and that temperature and humidity play a more important role than population factors in driving seasonality of transmission $[18,19]$. Importantly, the role of influenza transmission in schools (and subsequently to households) is probably very limited in Cambodia because they are closed from July to September [20].

This study provides data useful for accurate recommendations on influenza vaccination. People living in Cambodia would ideally receive vaccines by April - May in order to develop protective immunity before the peak season of transmission.

We were able to also identify severe influenza infections among hospitalized patients paralleling the same seasonality as observed within the NIC's ILI surveillance. To our surprise, few cases were detected among hospitalized patients with ALRI. We believe that this low frequency of cases may not be a reflection of the extent of influenzarelated severity, rather that it is explained by the delay in hospital admission of Cambodian patients presenting with severe respiratory infections. Indeed, most bacterial lung infections included in our hospital study were diagnosed among patients who attended hospital too late after the onset of respiratory symptoms for viral detection (average, 6 days; IPC's unpublished data). It is plausible that many of these bacterial infections were secondary infections from an initial influenza disease. Further testing for influenza using serology should be performed among patients with bacterial respiratory infections during the seasonal epidemics to establish this hypothesis. In addition, the average age of the patients presenting to hospital with ALRI was significantly higher $(\mathrm{p}<0.001)$ than patients with ILI symptoms since influenza is mainly found in children, it may explain the rate differences between both studies. In 2006, few influenza viruses were detected, as the NIC and its sentinel sites were just established in August 2006. In this year, all influenza-positive isolates belonged to influenza A/H3N2 sub-type which is consistent with influenza activity reported worldwide by WHO. Indeed, in 2006, a low influenza activity was observed and influenza A/H3N2 virus was the predominant subtype in many European and Asian countries [21]. In 2007, both influenza A subtypes as well as influenza B viruses co-circulated at comparable level. Among others, outbreaks of influenza B virus were also reported in 2007 in China, Hungary and in the United States [22]. In 2008, influenza A and B viruses were co-circulating as well but influenza A viruses represented two thirds of the strains detected. Similar general circulation patterns were observed worldwide in 2008 and, as in Cambodia, H3N2 subtype was responsible for most outbreaks in some European countries or in Japan [23].

Since the establishment of the NIC and the ILI surveillance system, we observed a regular increase in the influenza positivity rates in the samples that were tested. This could be linked to a higher influenza activity but also to an improvement of the system from patient recruitment (with adjustment of the case definition in 2008 for the fever criteria), to sample collection and transport to testing. Significant differences in the influenza positivity rate were observed between the sentinel sites. It was expected that paediatric hospitals will have a higher positive rate than adult hospitals, but interestingly, comparing the two paediatric hospitals, the one based in Phnom Penh produced more influenza-positive samples than the hospital located in Siem Reap, perhaps emphasizing the important role of the physician in the successful recruitment of patients who are likely to have influenza infection.

There are some limitations to the sentinel surveillance data. Sentinel data cannot be extrapolated precisely to the rest of the population, as the outpatients clinic serving sentinel sites were not truly representative. Random selection of patients is not yet well standardized and depends on the goodwill of physicians in participating in influenza surveillance. In addition, ILI consultation rates were not provided, and data is lacking on the catchment areas of the sentinel sites. As a result, little inferences can be made on disease burden or severity in Cambodia in general. Despite these problems, the system has been useful in meeting the purposes of influenza surveillance, identifying the predominant circulating strains in the community and allowing the formulation of guidelines for influenza vaccine composition for the subsequent year.

Since 2005, a total of eight human cases of influenza A/ H5N1 have been identified in Cambodia [24]. Interestingly, H5N1 human cases (e.g. in March 2007 and December 2008) were detected while there was evidence of background human influenza activities. As in other Asian countries, there is some evidence of endemicity of avian influenza H5N1 circulation in poultry in Cambodia [25]. There is little evidence for human-to-human transmission of the $\mathrm{H} 5 \mathrm{~N} 1$ virus. Additional mutations or reassortment events are probably required to permit efficient human-to-human spread which could trigger a pandemic $[26,27]$. Thus, if H5N1 virus infection in humans occurs during these seasonal epidemics, the risk of reassortment increases.

Even though there is little evidence of mild or asymptomatic H5N1 human infections, the increasing incidence 
of cases with influenza-like symptoms have been reported more frequently since 2005 [28]. In most countries, H5N1 testing is usually limited to symptomatic cases with a recent history of exposure to dead or sick poultry. Thus, if the H5N1-infected patients deny contact with the usual animal source of contamination, hospitalization and testing would be unlikely and the symptoms could be mistaken for seasonal flu. Others may not seek medical attention, assuming that the H5N1 infection is mild and does not require medical attention, leading to exposure of others. Hence, H5N1 virus detection by NICs should be systematic.

\section{Conclusion}

This study provides the first data regarding influenza activity in Cambodia, combining influenza-like illness surveillance and acute lower respiratory infection surveillance. It demonstrates that even though Cambodia is a tropical country geographically located in the northern hemisphere, influenza activity has a southern hemisphere transmission pattern. Together with the antigenic analysis of the circulating strains, it is now possible to provide better recommendations for influenza vaccination in Cambodia. The ILI surveillance system produced a higher number of seasonal influenza cases than the ALRI surveillance system. This system is therefore more useful for maximizing detection of seasonal influenza cases to generate data regarding vaccine composition, and antiviral susceptibility. Significantly, the parallel circulation of seasonal and avian influenza viruses represents a risk for pandemic by re-assortment during human co-infection. This highlights the importance to reinforce and develop the influenza surveillance systems (both ILI and ALRI); especially in countries where $\mathrm{H} 5 \mathrm{~N} 1$ virus infection has become endemic in poultry.

\section{Competing interests}

The authors declare that they have no competing interests.

\section{Authors' contributions}

SM performed analysis of the data and drafted the manuscript. SV, SL, SH, CH, CN, NA, MM, IB, SR, WZ, TK and ST participated in the design and coordination of the study. SV and DV revised the manuscript and did complementary analysis. PB conceived the study, participated in its design and coordination, and helped to draft the manuscript. All authors read and approved the final version of the manuscript.

\section{Acknowledgements}

We would like to thank for their contribution: Dr lan Barr (WHOCC, Melbourne); Dr Kdan Yuvatha, Dr Tum Kimly, Dr Mey Monyborin, Dr Sear Bunyoeui (physicians from the sentinel sites); Mrs Koi Sophanna, Mr Lut Mardy, Mr Rith Sareth, Mr Pan Vichea, Dr Ong Sivuth, Mr Mey Channa, Dr Monica Naughtin (Virology unit, IPC); Mr Un Thy, Ms Nut Dara, Dr But
Sokhal, Dr Ung Sam An (National Institute of Public Health, Cambodia); Dr Paul Kitsutani (US CDC, Cambodia).

\section{References}

I. Fact Sheet 211 influenza [http://www.who.int/mediacentre/ factsheets/2003/fs21//en/]. Access on 23rd April, 2009

2. Viboud C, Alonso W], Simonsen L: Influenza in tropical regions. PLoS Med 2006, 3(4):0468-047I.

3. Monto AS: Global burden of influenza: What we know and what we need to know. Int Congr Ser 2004, I 263:3-II.

4. National Influenza Centers [http://www.who.int/csr/disease/ influenza/centres/en]. Access on 23rd April, 2009

5. Monto AS: Epidemiology of viral respiratory infections. Am J Med 2002, I I 2(Suppl 6A):4S- 2 S.

6. World Health Organization: A practical guide to harmonizing virological and epidemiological influenza surveillance. World Health Organization, Regional Office for the Western Pacific, Manila, Philippines 2008 [http://www.wpro.who.int/internet/resources.ashx/CSR/ Publications/GuideToHarmonizingInfluenzaSurveillancerevised2302.pdf]. Access on 23rd April, 2009

7. Pujol-Bellau S, Vabret A, Legrand L, Dina J, Gouarin S, Petitjean-Lecherbonnier J, Pozzetto B, Ginevra C, Freymuth F: Development of three multiplex RT-PCR assays for the detection of $\mathbf{2}$ respiratory viruses. J Virol Methods 2005, I 26:53-63.

8. Kendal AP, Pereira MS, Skehel JJ: Concepts and Precedures for Laboratory-Base Influenza Surveillance. Geneva: World Health Organization; 1982.

9. Reagents for influenza virus diagnosis 2008 [http://www.influ enzacentre.org]

10. Nguyen Hang LK, Saito R, Ngiem HK, Nishikawa M, Shobugawa $Y$, Nguyen DC, Hoang LT, Huynh LP, Suzuki H: Epidemiology of influenza in Hanoi, Vietnam, from 2001 to 2003. J Infect 2007, 55:58-63.

II. Waicharoen S, Thawatsupha P, Chittaganpitch M, Maneewong $P$, Thanadachakul T, Sawanpanyalert $P$ : Influenza viruses circulating in Thailand in 2004 and 2005. Jpn J Infect Dis 2008, 61:32I-323.

12. Simon L: The global impact of influenza on morbidity and mortality. Vaccine 1999, I7(SuppI I):S3-SIO.

13. Hampson AW: Epidemiological data on influenza in Asian countries. Vaccine 1999, 17:S19-S23.

14. Logfren E, Fefferman NH, Naumov YN, Gorski J, Naumova EN: Influenza seasonality: underlying causes and modeling theories. J Virol 2007, 81:5429-5436.

15. de Arudda E, Hayden FG, McAuliffe JF, de Souza MA, Mota SB, McAuliffe $\mathrm{Ml}$, et al: Acute respiratory viral infections in ambulatory children of urban northeast Brazil. J Infect Dis 1991, 164:252-258.

16. Rao BL, Banerjee K: Influenza surveillance in Pune, India, 197890. Bull World Health Organ 1993, $71: 177-181$.

17. Dosseh A, Ndiaye K, Spiegel A, Sagna M, Mathiot C: Epidemiological and virological influenza survey in Dakar, Senegal: 19961998. Am J Trop Med Hyg 2000, 62:639-643.

18. Alonso WJ, Viboud C, Simonsen L, Hirano EW, Daufenbach LZ, Miller $M A$ : Seasonality of influenza in Brasil: a traveling wawe from the Amazon to the subtropics. Am J Epidemiol 2007, 165: 1434-1442.

19. Lowen AC, Mubareka S, Steel J, Palese P: Influenza virus transmission is dependent on relative humidity and temperature. PLoS Pathogens 2007, 3:1470-1476.

20. Longini IM Jr, Halloran ME: Strategy for distribution of influenza vaccine to high-risk groups and children. Am J Epidemiol 2005, 161:303-306.

21. World Health Organization: Recommended composition of influenza virus vaccines for use in the 2007-2008 influenza season. Wkly Epidemiol Rec 2007, 82:69-76.

22. World Health Organization: Recommended composition of influenza virus vaccines for use in the 2008-2009 influenza season. Wkly Epidemiol Rec 2008, 83:77-88.

23. World Health Organization: Recommended composition of influenza virus vaccines for use in the 2009-20I0 influenza season. Wkly Epidemiol Rec 2009, 84:65-76.

24. Buchy P, Mardy S, Vong S, Toyoda T, Miller M, Touch S, Dufourcq JB, Richner B, Tu PV, Tien Nguyen TK, Lim W, Peiris JSM, Van der Werf S: Influenza A/H5N I Virus Infection in Humans in Cambodia. J Clin Virol 2007, 39(3):164-8. 
25. Buchy P, Fourment M, Mardy S, Sorn S, Holl D, Ly S, Vong S, Enouf V, Peiris JSM, Van der Werf S: Molecular epidemiology of clade I influenza A viruses (H5NI), Southern Indochina Peninsula, 2004-2007. Emerg Infect Dis 2009, 15:164I-4.

26. Peiris JSM, Jong MD, Guan Y: Avian influenza virus (H5NI): A threat to human health. Clinical Microbiology Reviews 2007, 20(2):243-267.

27. Neumann G, Shinya K, Kawaoka Y: Molecular pathogenesis of H5N I virus infections. Antivir Ther 2007, 1 2:617-26.

28. Writing Committee of the Second World Health Organization Consultation on Clinical Aspects of Human Infection with Avian Influenza A $(\mathrm{H} 5 \mathrm{NI})$ Virus: Update on avian influenza $A(\mathbf{H} 5 \mathrm{NI})$ virus infection in humans. N Engl J Med 2008, 358(3):26I-273.

\section{Pre-publication history}

The pre-publication history for this paper can be accessed here:

http://www.biomedcentral.com/1471-2334/9/168/pre pub

Publish with Bio Med Central and every scientist can read your work free of charge

"BioMed Central will be the most significant development for disseminating the results of biomedical research in our lifetime. "

Sir Paul Nurse, Cancer Research UK

Your research papers will be:

- available free of charge to the entire biomedical community

- peer reviewed and published immediately upon acceptance

- cited in PubMed and archived on PubMed Central

- yours - you keep the copyright

Submit your manuscript here:

http://www.biomedcentral.com/info/publishing_adv.asp 